\title{
Sharing Beyond Peer-to-peer Trading: Collaborative (Open) Business Models as a Pathway to Smart Circular Economy in Electricity Markets
}

DOI:

10.1109/DCOSS49796.2020.00081

\section{Document Version}

Accepted author manuscript

Link to publication record in Manchester Research Explorer

Citation for published version (APA):

Montakhabi, M., Van Der Graaf, S., Ballon, P., \& Mustafa, M. A. (2020). Sharing Beyond Peer-to-peer Trading: Collaborative (Open) Business Models as a Pathway to Smart Circular Economy in Electricity Markets. In 2020 16th International Conference on Distributed Computing in Sensor Systems (DCOSS) (pp. 482-489) https://doi.org/10.1109/DCOSS49796.2020.00081

Published in:

2020 16th International Conference on Distributed Computing in Sensor Systems (DCOSS)

\section{Citing this paper}

Please note that where the full-text provided on Manchester Research Explorer is the Author Accepted Manuscript or Proof version this may differ from the final Published version. If citing, it is advised that you check and use the publisher's definitive version.

\section{General rights}

Copyright and moral rights for the publications made accessible in the Research Explorer are retained by the authors and/or other copyright owners and it is a condition of accessing publications that users recognise and abide by the legal requirements associated with these rights.

\section{Takedown policy}

If you believe that this document breaches copyright please refer to the University of Manchester's Takedown Procedures [http://man.ac.uk/04Y6Bo] or contact uml.scholarlycommunications@manchester.ac.uk providing relevant details, so we can investigate your claim.

\section{OPEN ACCESS}




\title{
Sharing Beyond Peer-to-peer Trading: Collaborative (Open) Business Models as a Pathway to Smart Circular Economy in Electricity Markets
}

\author{
Mehdi Montakhabi*, Shenja van der Graaf*, Pieter Ballon*, and Mustafa A. Mustafa $\mathbb{q}^{*}$ \\ *imec-SMIT, Vrije Universiteit Brussel, Pleinlaan 9, Brussels, 1050, Belgium \\ IDepartment of Computer Science, The University of Manchester, Manchester, M13 9PL, UK

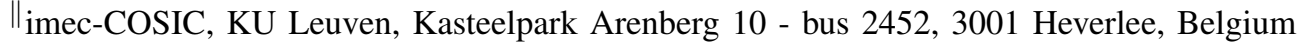 \\ Email: mehdi.montakhabi@vub.be
}

\begin{abstract}
This paper performs an analysis on emergent peerto-peer (p2p) electricity trading markets utilizing the resourcebased theory based on the sharing economy concept to identify possible opportunities for assets/data sharing amongst existing and emerging market players. First, the study introduces actors in the future electricity market and identifies their objectives. Second, valuable resources of each actor are recognized and categorized under physical and digital groups. Third, interested actors in each resource and benefits they can gain by having access to the resource are discussed. Last, a matrix of sharing opportunities amongst the actors in the electricity market is built and the current state of sharing is compared with the possibilities in the future. This paper provides and serves as a benchmark for implementing the sharing economy concept in future design of electricity markets. It highlights sharing opportunities as a means for circular economy in the electricity market. Implementing the identified sharing opportunities requires more collaborative (open) business models.
\end{abstract}

Index Terms-Open business model, sharing economy, circular economy, collaboration, peer-to-peer, smart grid, business model innovation, electricity market.

\section{INTRODUCTION}

While major knowledge in management science is built assuming scarcity of resources [1], sustainability attempts are made to make sure resources will sustain and suffice for future [2]. Sharing economy concept as one of the main building blocks of circular economy is considered to increase the efficiency of value creation and enhance sustainability [3].

Sharing economy is a novel paradigm to utilize others' underutilized resources without the transfer of ownership. Parties involved in sharing could be individuals, companies, public entities, etc. and shared resources could be physical assets or digital information (data) [4]. Sharing concept allows market players to move away from the traditional business models where they were tied to their limited resources and a clear border between the firm and its environment was imaginable [5].

Electricity market has witnessed a path towards smartness by the emergence and widespread use of Internet of Things (IoT) devices [6]. One of the well-known examples of IoT devices in the electricity grid is a smart meter - an advanced instrument with the capability of fine-grained metering of electricity and two-way communication of data [7]. Availability of IoT devices, as an enabler of sharing economy in the electricity market [8], together with technological advancements in provision of feasible solar panels and storage devices has opened a window of opportunity [9] towards more circular (sustainable) economy in the electricity market. Peer-to-peer trading of electricity is one of the promising areas towards sustainability in the electricity market [10].

Peer-to-peer trading of electricity enables prosumers/consumers to trade the electricity produced from their renewable energy sources with other peers in the same region [11]. The peer-to-peer trading part of this phenomenon is similar to most sharing concepts which require peer-to-peer interaction between involved parties [12]. To name some, Airbnb and Uber are businesses built on the sharing concept in a peer-to-peer setting.

Peer-to-peer trading of electricity has attracted scholars and practitioners' attention during past years [13], including security and privacy risks [14], [15] as well as secure solutions [16], [17]. However inadequate attention has been given to other (in some cases more feasible) opportunities for sharing economy in the electricity market. Considering the definition of sharing concept, sharing can extend its applications further than electricity trading/sharing amongst peers. This paper performs an analysis on emergent peer-to-peer electricity trading markets based on the resource-based theory (discussed in section III) and sharing economy concept to identify possible opportunities for assets and data sharing amongst existing and emerging actors in the electricity market. To the best of authors' knowledge, this is the first time the resourcebased theory is utilized to discover sharing opportunities in the electricity market.

The novel contributions of this paper are two-fold:

- First, it makes use of the resource-based theory to identify the resources of several actors with potential of sharing in the electricity market.

- Second, it suggests new possibilities beyond peer-to-peer trading of electricity for sharing amongst actors in the future electricity market. 
The paper is organised as follows. Section II gives details on the methodology used to identify opportunities for sharing in the current and future electricity markets. Section III identifies valuable resources of the current and new actors in the electricity market with the potential of sharing. Interested actors and the benefit they can gain by accessing each resource is discussed in this section. Section IV introduces opportunities for sharing in the future electricity market. Section V discusses sharing in the current versus future electricity market and introduces the limitations of this study and opportunities for future research. Section VI concludes the paper.

\section{PRELIMINARIES}

\section{A. Methodology}

The study follows a qualitative approach. In the first part of the study, resources of the electricity market actors, their market objectives, and possible interested actors for each resource are identified by literature review. Results of the literature review are validated by expert interview results. Twenty six interviews were conducted by authors in the context of the SNIPPET project ${ }^{1}$. Interviews were planned to cover several aspects of the current and future structure of the electricity market, actors in the market, their responsibilities, resources, objectives etc. Interviews were conducted face to face and via Skype. Each interview took between twenty to ninety minutes. Interviewees are academics and practitioners in the electricity market. They are selected from several stakeholder groups to provide a comprehensive view of the electricity market. Interviews were conducted between October 2019 and March 2020.

The second part of the study uses a matrix built on the results of the first part. The matrix has actors of the future electricity market in its axes. Cells of the matrix represent opportunities for sharing in the electricity market.

An opportunity is defined as a situation in which new products, services, markets, raw materials, and in general business models emerge through the formation of new meansends combinations [18]. In this paper, sharing opportunities are considered as a combination of existence of a valuable resource of an actor and another actor interested to gain access to that resource. The interested actor will benefit by accessing the resource.

The results of the matrix analysis are validated by two experts who are researchers working on the peer-to-peer electricity market and sharing economy field.

\section{B. Theoretical Framework - resource-based View}

The resource-based theory suggests an inside-out perspective on the reason for some market players' success in competition with others. It focuses on the resources inside boundaries of market players to build their competitive advantages. However, not all the resources are sources of competitive advantage [19]. The resource-based theory highlights the importance of VRIN (valuable, rare, imperfectly imitable and

\footnotetext{
${ }^{1}$ https://www.esat.kuleuven.be/cosic/project/snippet/
}

not substitutable) resources in building competitive advantage for actors in a given market [20]. In the resource-based theory, a competitive advantage is the coincidence of resource heterogeneity and immobility [19]. An inherent advice of the resource-based theory is to preserve the source of competitiveness, meaning VRIN resources [21].

An actor in the electricity market can be viewed as a bundle of resources under common governance (resource base) [22]. Resource base of an actor can have various components. Amongst the common types of resources are:

1) Physical resources: grid infrastructure, power plants, solar panels, etc.

2) Digital resources (data): smart meters' information, demand and supply information, etc.

Considering the nature of resources which are the case of sharing (non-VRIN resources), this study mostly focuses on the above-mentioned two types of resources.

Financial resources, human resources, upstream and downstream knowledge, administrative (governance-related) knowledge, and reputational resources are other categories of resources mentioned in literature [22].

\section{ACtors' Resources AND Interested PARTIES}

In this section, actors (existing and emerging) and their market objectives in the lectricity market are briefly introduced. Resources of each of the actors are identified. For the list of actors in the future electricity market, the study considers the future scenarios introduced in [4] and actors introduced based on the future scenarios in [5]. Resources of each actor are categorized under physical and digital groups. An overview of these resources is given in Table I.

1) Prosumers: Prosumers are the consumers who can also act as producers, i.e., generate and inject electricity into the grid. They are equipped with renewable energy sources (e.g., solar panels), storage devices (batteries, electric vehicles, etc.), various (smart) appliances, smart meters, and home energy management systems. Their main objectives are to minimise cost (electricity bill), maximise profit (income), and mitigate the dependency on the grid by maximising their resource utilisation. Prosumers have following valuable resources:

- Renewable Energy Sources (RES) are mini generators (e.g., solar panel) located on prosumers' premises. The electricity they generate is usually consumed by their owners, but electricity may also be injected into the grid.

- Home batteries are storage devices which make it possible to make a lag between provision and consumption of electricity produced/purchased by prosumers or any other actor which gets access to prosumers' storage capacity.

- Electric Vehicle (EV) is a vehicle which uses one or more electric motors for propulsion and battery to store electricity.

- EV battery is the battery installed on EVs. In contrast to home battery that can only store electricity locally, the $\mathrm{EV}$ battery can also be used to transport electricity. 
- EV charging station is an equipment that is used to connect EVs to the electrical grid for charging / discharging electricity.

- Smart appliances are appliances which are connected with each other as well as other intelligent home devices. They can be accessed and controlled remotely.

- Smart meters are advanced metering devices which can measure the amount of electricity flowing in both directions (from the grid to the house and vice versa) and perform two-way communications with other entities.

- Home energy Management System (HMS) is a technology platform comprised of both hardware and software that allows the user to monitor energy usage and production and to manually control and/or automate the use of energy within a household.

- Demand Information: This includes all information about the amount and pattern of the electricity requirement of prosumers.

- Supply Information: This includes all information about the amount and pattern of the electricity production by prosumers's RES.

- Flexibility Information: Refers to the extent to which a prosumer can modify electricity production or consumption in response to variability, expected, or otherwise.

2) Representative (Non-existing role in the current market setting): Representatives are a new actor in the peer-topeer electricity market. Their role is to manage their clients' physical assets (i.e., RES, home and EV battery, etc.) and information as well as represent them in the peer-to-peer market [4], [5]. The presence of a representative increases the involvement of citizens in the peer-to-peer electricity markets. Representatives transform passive citizens' roles to active ones in the market. It is expected that they facilitate sharing opportunities between prosumers and the other established market players. Their objective is to minimise cost and increase profits of their customers (i.e., prosumers). There is a subtle point about representatives' resources. They do not own their clients resources. Resources of the representatives mostly belong to categories other than physical and digital resources. To name some: upstream knowledge (sourcing knowledge, as well as product/service- and process-related technological knowledge), downstream knowledge (critical to the interface with customers, and related to marketing, sales, distribution and after-sales service activities), administrative (governance-related), and reputable resources (brand names, a good reputation for honest business dealings, etc.).

3) Broker (Non-existing role in the current market setting): A broker is an intermediate (neutral) actor that facilitates the trading in peer-to-peer electricity markets. They have access to information of all the parties participating in the peer-topeer electricity trading market and their transactions. Its main objective is to clear the peer-to-peer market while respecting the grid's constraints as well as prosumers' preferences.

Brokers special position in the market is not because of the physical or digital resources, upstream or downstream knowledge, brand and other common resources. This position is mostly the fruit of first mover advantage (which gives a player a sheer part of the market) or the legal monopoly. To elaborate further, brokers will have access to all the information that is contained in a typical prosumer bid - volume of electricity offered, requested price, demand/supply bid, any user preferences (specific type of source of the electricity, location, etc.), grid access point (location), the source of the electricity (solar, wind, biomass, etc.).

4) Aggregator: An aggregator is a market player that provides ancillary services to grid operators, mainly in the balancing electricity market, by aggregating prosumers' flexibility and trading this aggregate flexibility on the market. Its main objective is to maximise profit by trading ancillary services to the grid operators. To achieve this, they have access to the following information:

- Clients' supply capacity: It includes the capacity and pattern of aggregators' clients' supply of electricity to the grid.

- Clients' demand capacity: It includes the capacity and pattern of aggregators' clients' demand of electricity from the grid.

- Clients' balancing capacity: The flexibility of aggregators' clients which can be served to the grid.

5) Retailer: Retailers are the market players who are responsible for providing prosumers with electricity (when the prosumers' RES do not generate sufficient amount of electricity). They buy electricity in bulk from generators in the wholesale market and sell it to prosumers in the retail market. In the current market settings, retailers are also obliged to buy any of the clients' electricity that is not traded in the p2p electricity market and still injected back to the grid. Their main objective is to maximise profit, while ensuring that their clients demand for electricity is met. Retailers have access to the following information:

- Customers' demand information: It indicates how much electricity is consumed by retailers' clients in a specific period of time. This information is valuable to make any estimates about the future demand of the market.

- Customers' supply information: It indicates how much electricity is injected to the grid by retailers' clients in a specific period of time. Similarly, this information is valuable to make any estimates about the future demand/supply of the market.

6) Distribution System Operator (DSO): DSOs are the operating managers (and sometimes owners) of energy distribution networks [23], operating at low and medium voltage levels. Their main objective is to avoid congestion. DSOs have following valuable resources:

- Distribution grid infrastructure: Distribution grid refers to the final stage of the electrical grid in which electricity is distributed to homes, industry, and other end use products. Distribution is the process of reducing power to safe customer-usable levels, and delivering the electric power to the grid. 
TABLE I

VALUABLE RESOURCES OF EACH ACTOR IN THE FUTURE ELECTRICITY MARKETS AND INTERESTED ACTORS IN EACH RESOURCE

\begin{tabular}{|c|c|c|}
\hline & Physical Resources $\leftarrow$ Interested parties & Digital Resources (Data) - Interested parties \\
\hline Prosumer (Pro) & $\begin{array}{l}\text { RES } \leftarrow \text { Pro, Rep } \\
\text { Home Battery } \leftarrow \text { Pro, Rep } \\
\text { EV } \leftarrow \text { Pro, Rep } \\
\text { EV charging station } \leftarrow \text { Pro, Rep, DSO } \\
\text { EV battery } \leftarrow \text { Pro, Rep } \\
\text { HEMS } \leftarrow \text { Pro, Rep } \\
\text { Smart Appliance } \leftarrow\end{array}$ & $\begin{array}{l}\text { Smart Meters } \leftarrow \text { Rep, Ret, DSO, TSO } \\
\text { Demand } \leftarrow \text { Rep, Br, Ret, DSO, TSO } \\
\text { Supply } \leftarrow \text { Rep, Br, Ret, DSO, TSO } \\
\text { Flexibility } \leftarrow \text { Rep, DSO, TSO }\end{array}$ \\
\hline Representative (Rep) & $\begin{array}{l}\text { Clients' RES } \leftarrow \text { Pro, Rep } \\
\text { Clients' Batteries } \leftarrow \text { Pro, Rep } \\
\text { Clients' EVs } \leftarrow \text { Pro, Rep } \\
\text { Clients' EV Charging Stations } \leftarrow \text { Pro, Rep, DSO } \\
\text { Clients' Batteries of EVs } \leftarrow \text { Pro, Rep } \\
\text { Clients' HMS } \leftarrow \text { Pro, Rep }\end{array}$ & $\begin{array}{l}\text { Clients' Smart Meters } \leftarrow \text { Ret, DSO, TSO } \\
\text { Clients Demand } \leftarrow \mathrm{Br} \text {, Ret, DSO, TSO } \\
\text { Clients' Supply } \leftarrow \mathrm{Br} \text {, Ret, DSO, TSO } \\
\text { Clients' Flexibility } \leftarrow \text { DSO, TSO }\end{array}$ \\
\hline Broker (Br) & & $\begin{array}{l}\text { Sellers'supply information } \leftarrow \text { Ret, DSO, TSO } \\
\text { Sellers'offered price } \leftarrow \text { Ret } \\
\text { Buyers'demand information } \leftarrow \text { Ret, DSO, TSO } \\
\text { Buyers offered price } \leftarrow \text { Ret } \\
\text { Clearance price } \leftarrow \text { Ret } \\
\text { Total traded volume } \leftarrow \text { Ret, DSO, TSO, Gen }\end{array}$ \\
\hline Aggregator (Agg) & & $\begin{array}{l}\text { Clients'supply capacity } \leftarrow \text { TSO } \\
\text { Clients'demand capacity } \leftarrow \text { TSO } \\
\text { Clients'balancing capacity } \leftarrow \text { TSO }\end{array}$ \\
\hline Retailer (Ret) & & $\begin{array}{l}\text { Customers'demand information } \leftarrow \text { DSO, TSO } \\
\text { Customers'supply information } \leftarrow \text { DSO, TSO }\end{array}$ \\
\hline DSO & Distribution grid infrastructure $\leftarrow$ Pro, Rep, Ret & $\begin{array}{l}\text { Smart meters' inflow information } \leftarrow \text { Rep, Ret } \\
\text { Smart meters' outflow information } \leftarrow \text { Rep, Ret } \\
\text { Congestion information } \leftarrow \text { Rep, Ret }\end{array}$ \\
\hline TSO & Transmission grid Infrastructure $\leftarrow$ TSO, Gen, Pro & $\begin{array}{l}\text { Balancing information } \leftarrow \mathrm{Agg} \text {, Ret, TSO, Gen } \\
\text { Congestion information } \leftarrow \mathrm{Agg} \text {, TSO, Gen } \\
\text { Demand/supply pred. } \leftarrow \mathrm{Agg} \text {, Ret, DSO, TSO, Gen }\end{array}$ \\
\hline Generator (Gen) & & Power plants (coal, gas, nuclear, etc.) $\leftarrow$ Ret \\
\hline
\end{tabular}

- Smart meters' inflow information: It includes the information regarding the amount and pattern of consumption at any smart meter. The more real-time this information, the more valuable it is. Modern smart meters make it possible to read the smart meters' information in a real time pattern. DSO is the sole actor has access to this information through the smart meters installed at clients' premises.

- Smart meters' outflow information: Similar to the smart meters' inflow, it includes the information regarding the amount and pattern of electricity provisioned at any smart meter. The more real-time this information, the more valuable it is.

- Congestion information: Congestion can be defined as violations of network constraints (voltage and frequency) due to high electricity demand or excess electricity generation.

7) Transmission System Operator (TSO): TSO is responsible for maintaining the transmission network, balancing the grid, and charging suppliers transmission network fees based on the electricity consumption/provision data of the suppliers' customers in the grid. TSO's main objective is to balance the grid. A TSO has the following valuable resources:

- Transmission grid Infrastructure: Electricity transmission is the bulk movement of electricity from a generating site, such as a power plant, to an electrical substation. The interconnected lines which facilitate this movement are known as a transmission grid.

- Balancing information: Electricity balancing encompasses all actions and processes, on all timelines, through which TSOs ensure, in a continuous way, the system frequency is within a predefined stability range as set forth in the Network Code on System Operation, and complies with the amount of reserves needed with respect to the required quality. This includes deficit, surplus, and reserves at any time period.

- Congestion information: Transmission congestion happens when scheduled market transactions (generation and load) result in power flow over a transmission element that exceeds the available capacity for that element.

- Demand/supply prediction: It includes all the estimates that TSOs can have based on the comprehensive information they receive for the balancing purposes.

8) Generators: Generators are the entities who generate electricity to meet the demand for electricity by consumers/prosumers. Their main objective is to maximise profit by trading electricity in the wholesale and/or balancing market. They have the following valuable resources:

- Power plant: It is an industrial facility for the generation of electric power. Power plants are connected to electricity grids. Their energy source varies widely. Most of them burn fossil fuels (e.g. coal, oil, and natural gas). Cleaner energy sources of power plants include nuclear power, and an increasing use of renewables (e.g. solar, 
wind, wave, and hydroelectric).

\section{OPPORTUNITIES FOR SHARING}

In this section, the existing (or new) market players who would be interested in utilising (some of the) resources of other actors, identified in the previous section, and the attainable benefit by accessing the resource are discussed. This part answers two questions: who is interested in the resource? and what benefit can the interested actor gain?

1) Prosumers:

- Renewable Electricity Sources (RES): Other prosumers/consumers (or representatives on behalf of them) by accessing prosumers' RES can produce renewable electricity. The owner of the produced electricity is the party which it is shared with. In a sense, rather than trading the electricity generated by the RES, prosumers can lend/rent their RES for a specific time period.

- Batteries: Other prosumers/consumers (or representatives on behalf of them) by accessing prosumers' batteries can store electricity. The owner of the stored electricity is the party which the battery is shared with. Renting out the RES and the battery in combination should be the most beneficial for both - the owner and the renter.

- Electric Vehicle (EV) Electric vehicles can be used by other prosumers in idle time. Car sharing initiatives in a peer-to-peer manner is imaginable for this type of sharing. Representatives can represent underutilized capacity of electricity vehicles in a more efficient way on behalf of owners of EVs.

- EV battery: Other prosumers are interested in it as a portable storage device. People can sell $2 \mathrm{kw}$ to a user who leaves close to your work place. Rather than feeding it to the grid at your home location, you can transport this energy with your EV and inject it to the grid at your work location, potentially saving from grid use fees. Representatives can represent their clients' EV batteries in a more efficient way.

- EV charging station: EV charging stations can be used by other prosumers in idle times. It requires to bring the cars to the location of the station to charge them. Other prosumers are interested to use the EV charging stations for charging their EVs. Representatives are also interested in expanding their service basket and to more efficiently share charging stations on behalf of the owners. DSOs would be interested in it as a means to help the congestion problem without occupying the distribution grid's capacity.

- Smart meters: People cannot share the smart meter, but the data it generates is valuable to be shared. Considering the frequency of access to the smart meter data, it reveals information which are highly valued by several actors. DSOs value this information for billing and solving congestion problem, TSOs for balancing and retailers for customers consumption/production estimation purposes. Representatives can represent this information of behalf of their clients.
- Home energy Management System (HMS): As the case for the smart meter, probably the data generated by these systems are the most valuable. Representatives can use this data for participating in various markets. It is unclear how one can benefit from sharing the system itUnless, a neighbour (other prosumer) could use the system's functionality as well. In a sense, the neighbour (or any user) could send the data of their assets and let the home management system of another user make intelligent decisions for them. It is yet to be seen how practical this solution is. It might well work in apartment buildings, where several flats use only one home management system.

- Demand Information: Representatives are interested to have this information because it enables them to better represent their clients' demand and decide on the way to supply (purchasing from other prosumers, purchasing from grid, using the battery capacity, etc.). Retailers can plan on their electricity provision based on forecasts which are mainly based on their clients demand/supply information. DSOs can use this data to better handle the distribution grid congestion problem. TSOs can better balance the grid by having this information. Brokers are interested in the part of this information which would be traded in peer-to-peer electricity market through their channel.

- Supply Information: Representatives are interested in this information because it enables them to better represent their clients supply and decide on the way to sell/share (selling to other prosumers, selling to the grid, using the battery capacity to store the produced electricity, etc.). Retailers can plan on their electricity provision based on forecasts which are mainly based on their clients demand/supply information. DSOs can use this data to better handle the distribution grid congestion problem. TSOs can better balance the grid by having this information. Brokers are interested in the part of this information which would be traded in peer-to-peer electricity market through their channel.

- Flexibility: DSOs are interested in flexibility capacity to overcome the congestion problem. TSOs can use this capacity as a means to balance the electricity grid. Representatives can represent this capacity on behalf of clients to other interested parties. Aggregators do the same type of representation for their clients in the current electricity market.

2) Representative: As discussed in the presentation of representatives in the previous section, the type of resources representatives own is mostly not the case of sharing. However representatives (on behalf of prosumers) have access to the same valuable resources as prosumers and facilitate sharing. What differentiates representatives' role in sharing than prosumers is that representatives have the aggregate capacity of their clients to share. The aggregation of clients' resources in hands of a representative, gives it a service basket and 
leverage its position to negotiate and enter to markets that is not possible for a single prosumer to access.

3) Brokers:

- Sellers' supply information: This information is about the capacity for supply and not necessarily all the supply capacity is traded in peer-to-peer market. The information is useful for planning purposes. DSOs are interested in the supply information to have a better congestion management in the distribution grid. TSOs can enhance balancing planning by access to this information. Retailers can have a better planning for their electricity demand from generators which later they will supply in the retail market.

- Sellers' offered price: Access to this information helps retailers in their pricing. Retailers' pricing is in direct competition with the supply price in peer-to-peer trading market.

- Buyers' demand information: This information is about the capacity for demand and not necessarily all the demanded amount is traded in the peer-to-peer market. The information is useful for planning purposes. DSOs are interested in the demand information to have a better congestion management in the distribution grid. TSOs can have a better balancing planning by access to this information. Retailers can have a better planning for their electricity demand from generators which later they will supply in the retail market.

- Buyers' offered price: Access to this information helps retailers in electricity pricing. It indicates potential customers willingness to pay. It is also worth mentioning this willingness is for the pee-to-peer market. Considering that retailers nowadays are also offering green electricity to their customers, it would help retailers to tailor their offering in that product segment.

- Clearance price: It is the price for complementary/substitute service of retailers. It is expected that retailers' pricing is directly impacted by this information.

- Total traded volume: Retailers and generators can adjust their pricing and supply by knowing the actual traded amount of electricity in the peer-to-peer trading market. DSOs can better manage the congestion problem in the distribution grid. TSOs can better balance the grid by knowing this information.

Consideration: What defines the broker's position in the market is the type of information that they have access to. It seems some of this information (seller' supply and price information, and buyers' demand information and offered price) are VRIN resources that despite the existence of other interested parties, brokers are not supposed to share them.

4) Aggregator:

- Clients' supply capacity: TSOs are interested in this information for prevention of congestion in the transmission grid.

- Clients' demand capacity: TSOs are interested in this information for prevention of congestion in the transmission grid.
- Clients' balancing capacity: TSOs are interested because of the use of this capacity in balancing of the grid.

5) Retailer:

- Customers' demand information: DSOs are interested in this information for distribution grid congestion prevention. TSOs are interested because of balancing purposes.

- Customers' supply information: As above.

6) Distribution System Operator (DSO):

- Distribution grid infrastructure: Prosumers are interested in the distribution grid to receive their electricity (purchased in the retail or peer-to-peer market) through it. Connectivity to the grid is also a necessity to receive the balancing services which translates into the stability of the electricity stream. Representatives have the same dependency/interest as prosumers regarding the distribution grid. The distribution grid is a means which makes the existence of retailers' services meaningful. Meaning that they can only deliver what they sell if the client is connected to the grid.

- Smart meters' inflow information: Retailers are interested in this information because it reveals their customers' consumption behavior. It is valuable for pricing and planning purposes. Representatives are also interested in this information because they are the sellers in the peer-to-peer market. electricity sold in the peer-to-peer market is in competition with retailers' offers. So it has a similar value for representatives. Considering the level of expertise of prosumers, the required expertise to process this information is absent in individual prosumer.

- Smart meters' outflow information: As above.

- Congestion information: Representatives are interested in this information because it shows where is more prone for peer-to-peer trading (considering that peer-to-peer trading of electricity may cause congestion problem in the distribution grid). Retailers have similar interest as representatives for this information.

7) $\mathrm{TSO}$ :

- Transmission grid infrastructure: Generators and prosumers are already making use of this infrastructure by using it as a transposition means for their traded electricity.

- Balancing information: Active players in the balancing market are the interested parties. It includes retailers, aggregators and generators. Other TSOs (neighboring countries) are interested in this data because of the balancing purposes.

- Congestion information: Aggregators, other TSOs and generators are interested actors in this information. As a source of balancing solution this information is meaningful for the interested actors where is a good node to offer their balancing services.

- Demand/supply prediction: Active players in the balancing market are the interested parties. It includes retailers, aggregators and generators. Other TSOs (neigh- 
TABLE II

Sharing Opportunities in the CurRent Versus Future Electricity Market

\begin{tabular}{|c|c|c|c|c|c|c|c|c|}
\hline & Pro & Rep & Bro & Agg & Ret & DSO & TSO & Gen \\
\hline Pro & $\begin{array}{l}\text { Physical devices: } \\
\text { - RES } \\
\text { - Batteries } \\
\text { - EV } \\
\text { - EV charging station } \\
\text { - Battery of EV } \\
\text { - HMS }\end{array}$ & $\begin{array}{l}\text { Physical devices: } \\
\text { - RES } \\
\text { - Batteries } \\
\text { - EV } \\
\text { - EV charging station } \\
\text { - Battery of EV } \\
\text { - HMS } \\
\text { Data: } \\
\text { - SM info } \\
\text { - Demand info } \\
\text { - Supply info } \\
\text { - Flexibility }\end{array}$ & $\begin{array}{l}\text { Data: } \\
\bullet \text { Demand } \\
\text { info } \\
\text { - Supply info }\end{array}$ & & $\begin{array}{l}\text { Data: } \\
\text { - SM info } \\
\text { - Demand info } \\
\text { - } \underline{\text { Supply info }}\end{array}$ & $\begin{array}{l}\text { Data: } \\
\text { - SM info } \\
\text { - Demand info } \\
\text { - Supply info } \\
\text { - Flexibility }\end{array}$ & $\begin{array}{l}\text { Data: } \\
\text { - } \underline{\text { SM info }} \\
\text { - } \underline{\text { Demand info }} \\
\text { - Supply info } \\
\text { - Flexibility }\end{array}$ & \\
\hline Rep & $\begin{array}{l}\text { Physical devices: } \\
\text { - Clients' RES } \\
\text { - Clients' Batteries } \\
\text { - Clients' EV } \\
\text { - Clients' EV charging station } \\
\text { - Clients' Battery of EV } \\
\text { - Clients' HMS }\end{array}$ & $\begin{array}{l}\text { Physical devices: } \\
\text { - Clients' RES } \\
\text { - Clients' Batteries } \\
\text { - Clients' EV } \\
\text { - Clients' EV charging station } \\
\text { - Clients' Battery of EV } \\
\text { - Clients' HMS }\end{array}$ & $\begin{array}{l}\text { Data: } \\
\text { - Clients' } \\
\text { Demand } \\
\text { info } \\
\text { - Clients' } \\
\text { Supply } \\
\text { info }\end{array}$ & & $\begin{array}{l}\text { Data: } \\
\text { - Clients' SM info } \\
\text { - Clients' Demand info } \\
\text { - Clients' Supply info }\end{array}$ & $\begin{array}{l}\text { Data: } \\
\text { - Clients' SM info } \\
\text { - Clients' Demand info } \\
\text { - Clients' Supply info } \\
\text { - Clients' Flexibility }\end{array}$ & $\begin{array}{l}\text { Data: } \\
\text { - Clients' SM info } \\
\text { - Clients' Demand info } \\
\text { - Clients' Supply info } \\
\text { - Clients' Flexibility }\end{array}$ & \\
\hline Bro & & & & & $\begin{array}{l}\text { Data: } \\
\text { - Sellers' supply info } \\
\text { - Sellers' offered price } \\
\text { - Buyers' demand info } \\
\text { - Buyers offered price } \\
\text { - Clearance price } \\
\text { - Total traded volume }\end{array}$ & $\begin{array}{l}\text { Data: } \\
\text { - Sellers' supply info } \\
\text { - Buyers' demand info } \\
\text { - Total traded volume }\end{array}$ & $\begin{array}{l}\text { Data: } \\
\text { - Sellers' supply info } \\
\text { - Buyers' demand info } \\
\text { - Total traded volume }\end{array}$ & $\begin{array}{l}\text { Data: } \\
\text { - Total traded } \\
\text { volume }\end{array}$ \\
\hline Agg & & & & & & & $\begin{array}{l}\text { Data: } \\
\text { Clients' supply capacity } \\
\text { Clients' demand capacity } \\
\text { Clients' balancing capacity }\end{array}$ & \\
\hline Ret & & & & & & $\begin{array}{l}\text { Data: } \\
\text { Customers' demand info } \\
\text { Customers' supply info }\end{array}$ & $\begin{array}{l}\text { Data: } \\
\text { Customers' demand info } \\
\text { Customers' supply info }\end{array}$ & \\
\hline DSO & $\begin{array}{l}\text { Physical devices: } \\
\text { - Distribution grid } \\
\text { infrastructure }\end{array}$ & $\begin{array}{l}\text { Physical devices: } \\
\text { - Distribution grid } \\
\text { infrastructure } \\
\text { Data: } \\
\text { - SM inflow info } \\
\text { - SM outflow info } \\
\text { - Congestion info }\end{array}$ & & & $\begin{array}{l}\text { Physical devices: } \\
\text { - Distribution grid } \\
\text { infrastructure } \\
\text { Data: } \\
\text { - SM inflow info } \\
\text { - } \text { SM outflow info } \\
\text { - Congestion info }\end{array}$ & & & \\
\hline TSO & & & & $\begin{array}{l}\text { Data: } \\
\text { - Balancing info } \\
\text { - Congestion } \\
\text { info } \\
\text { - Demand/suppl } \\
\text { y prediction }\end{array}$ & $\begin{array}{l}\text { Data: } \\
\text { - Balancing info } \\
\text { - Demand/supply } \\
\text { prediction }\end{array}$ & $\begin{array}{l}\text { Data: } \\
\text { - Demand/supply } \\
\text { prediction }\end{array}$ & $\begin{array}{l}\text { Physical devices: } \\
\text { - Transmission grid } \\
\text { Infrastructure } \\
\text { Data: } \\
\text { - Balancing info } \\
\text { - Congestion info }\end{array}$ & $\begin{array}{l}\text { Data: } \\
\text { - Balancing info } \\
\text { - Congestion } \\
\text { info } \\
\text { - Demand/suppl } \\
\text { y prediction }\end{array}$ \\
\hline Gen & & & & & $\begin{array}{l}\text { Physical devices: } \\
\text { - Power plants }\end{array}$ & & & \\
\hline
\end{tabular}

boring countries) are interested in this data because of the balancing purposes. $D S O s$ are also interested in this data because of the implications that it could have on the congestion in the distribution grid.

\section{8) Generators:}

- Power plant: Retailers are interested in the production capacity of power plants rather than buying the electricity produced by them. Retailers can keep it as a reserve for balancing purposes. This scenario makes sense if sharing the capacity is more beneficial for generators rather than selling the output electricity.

\section{DISCUSSION}

\section{A. Sharing in the Current Versus Future Electricity Market}

As explained earlier, a sharing opportunity is a situation which there is at least one party else than the owner of a resource interested in accessing the resource. Knowing the actors in the electricity market, their resources and interested actors in each resource in Section III, we can identify the opportunities for sharing in the electricity market. Table II shows a matrix consisting all sharing opportunities in the electricity market. Actors are building the two axes of the matrix. Each cell of the matrix represents a combination of two different or same actors as parties involved in sharing. The content of each cell is the list of resources the party in the left column will share with the party in the top row. Underlined 
items are shared amongst the involved actors in the current electricity market. The rest are the opportunities for sharing in the future.

Considering the discussed sharing opportunities, it is expected that the electricity market faces the entrance of new actors (e.g. platform owners, complementary service providers, etc.) to facilitate sharing. There is a possibility that representatives extend their roles and seize these opportunities.

Aggregators somehow now play the mixed role of the representative and the broker, to some extent. In the future, the aggregators could move to play the role of the representative or the broker. However, the question is "Is it going to be a single player playing the roles of aggregator, broker, and representative?" It could be the case that the aggregators' role evolves to play these three roles or maybe as the aggregator evolves, it becomes less cost-effective to play all these roles, so there is a need for three distinct players to play these roles.

\section{B. Limitations and opportunities for Future Research}

This research has limitations that could be overcome in future studies. First, the study identifies sharing opportunities in the electricity market based on the existence of a valuable resource and an interested party. In reality there are considerations (e.g. security and privacy concerns, technical and legal limitations, etc.) which do not let all opportunities to materialize. It is valuable to perform an in-depth security and privacy analysis of identified sharing opportunities. Legal possibility and application of GDPR on the data protection is another void for studying the identified opportunities. Second, opportunities are identified based on the roles as a result of future scenarios in the electricity market. There is always a possibility that disruptive innovations alter the whole market. This study does not cover probable disruptions.

\section{CONClusions}

By listing the valuable resources of the current and future actors in the electricity market, based on the resource-based theory, actors' resources are categorized in two main groups, physical assets and digital assets (data). Existing sharing and the involved parties in the current electricity market are introduced. Opportunities for sharing amongst the actors in the electricity market are introduced by use of a matrix built up on actors in the future electricity market. The outcome of this study shows new voids towards smart circular economy.

\section{ACKNOWLEDGMENT}

This work was supported in part by the Research Council KU-Leuven: C16/15/058 and by the Flemish Government through FWO SBO project SNIPPET S007619. Mustafa A. Mustafa is funded by the Dame Kathleen Ollerenshaw Fellowship awarded by The University of Manchester. For proofreading, the authors would like to thank Hadi Montakhabi, Hong Nhung Truong, and Andrea Balmes.

\section{REFERENCES}

[1] R. B. Norgaard, "Economic indicators of resource scarcity: a critical essay," Journal of Environmental Economics and Management, vol. 19, no. 1, pp. 19-25, 1990.

[2] R. M. Solow, "25. sustainability: an economist's perspective," Economics of the environment: Selected readings, 2019.

[3] H. Heinrichs, "Sharing economy: a potential new pathway to sustainability," GAIA-Ecological Perspectives for Science and Society, vol. 22, no. 4, pp. 228-231, 2013.

[4] M. Montakhabi, A. Madhusudan, S. van der Graaf, A. Abidin, and M. A. Mustafa, "Sharing economy in future electricity markets: Security and privacy analysis," in Proc. of Workshop on Decentralized IoT Systems and Security (DISS), in conjunction with NDSS, 2020.

[5] M. Montakhabi, F. Zobiri, S. Van Der Graaf, G. Deconinck, D. Orlando, S. Vanhove, R. Callaerts, and M. A. Mustafa, "New roles in peer-to-peer electricity markets:value network analysis," in 6th IEEE International Energy Conference (ENERGYCON), 32020.

[6] M. Yun and B. Yuxin, "Research on the architecture and key technology of internet of things (iot) applied on smart grid," in 2010 International Conference on Advances in Energy Engineering. IEEE, 2010, pp. 6972.

[7] S. S. S. R. Depuru, L. Wang, V. Devabhaktuni, and N. Gudi, "Smart meters for power grid - challenges, issues, advantages and status," in 2011 IEEE/PES Power Systems Conference and Exposition. IEEE, 2011, pp. 1-7.

[8] T. Puschmann and R. Alt, "Sharing economy," Business \& Information Systems Engineering, vol. 58, no. 1, pp. 93-99, Feb 2016.

[9] Y. Parag and B. K. Sovacool, "Electricity market design for the prosumer era," Nature energy, vol. 1, no. 4, pp. 1-6, 2016.

[10] J. Murkin, R. Chitchyan, and A. Byrne, "Enabling peer-to-peer electricity trading," in ICT for Sustainability 2016. Atlantis Press, 2016.

[11] C. Zhang, J. Wu, C. Long, and M. Cheng, "Review of existing peer-topeer energy trading projects," Energy Procedia, vol. 105, pp. 2563-2568, 2017.

[12] A. Sundararajan, "Peer-to-peer businesses and the sharing (collaborative) economy: Overview, economic effects and regulatory issues," Written testimony for the hearing titled The Power of Connection: Peer to Peer Businesses, 2014.

[13] O. Jogunola, A. Ikpehai, K. Anoh, B. Adebisi, M. Hammoudeh, S.Y. Son, and G. Harris, "State-of-the-art and prospects for peer-to-peer transaction-based energy system," Energies, vol. 10, no. 12, p. 2106, 2017.

[14] M. A. Mustafa, S. Cleemput, and A. Abidin, "A local electricity trading market: Security analysis," in 2016 IEEE PES Innovative Smart Grid Technologies Conference Europe (ISGT-Europe). IEEE, 2016, pp. 1-6.

[15] I. Symeonidis, J. Schroers, M. A. Mustafa, and G. Biczók, "Towards systematic specification of non-functional requirements for sharing economy systems," in 2019 15th International Conference on Distributed Computing in Sensor Systems (DCOSS). IEEE, 2019, pp. 423-429.

[16] A. Abidin, A. Aly, S. Cleemput, and M. A. Mustafa, "An MPC-based privacy-preserving protocol for a local electricity trading market," in 15th Int. Conf. on Cryptology and Network Security (CANS 2016), ser. LNCS, vol. 10052. Springer, 2016, pp. 615-625.

[17] _ "Secure and privacy-friendly local electricity trading and billing in smart grid," arXiv preprint arXiv:1801.08354, 2018.

[18] J. T. Eckhardt and S. A. Shane, "Opportunities and entrepreneurship," Journal of management, vol. 29, no. 3, pp. 333-349, 2003.

[19] P. M. Madhani, "Resource based view (rbv) of competitive advantage: an overview," Resource Based View: Concepts and Practices, Pankaj Madhani, ed, pp. 3-22, 2010.

[20] J. Barney, "Firm resources and sustained competitive advantage," Journal of management, vol. 17, no. 1, pp. 99-120, 1991.

[21] J. B. Barney, "Resource-based theories of competitive advantage: A tenyear retrospective on the resource-based view," Journal of management, vol. 27, no. 6, pp. 643-650, 2001.

[22] A. VERBEKE, International Business Strategy: Rethinking the Foundations of Global Corporate Success. CAMBRIDGE University Press, 2013.

[23] R. D'Hauwers, J. van der Bank, and M. Montakhabi, "Trust, transparency and security in the sharing economy: What is the government's role?” Technology Innovation Management Review, vol. 10, no. 5, 2020. 